REVIEW ARTICLE

\title{
PROFESSOR LAZZARINI'S CONCEPTS IN DISPLACEMENT MEASUREMENTS AND ANALYSIS STILL VALID AND INSPIRING
}

\author{
Witold Prószyński \\ Warsaw University of Technology \\ Faculty of Geodesy and Cartography \\ Section of Engineering Surveying and Detail Surveys \\ Warsaw, Poland
}

It is not possible to describe in detail all the scientific and technological achievements of Professor Lazzarini in the area of displacement measurements and analysis. They are still widely known in our country and are remembered in several research centers abroad. In my opening address I shall concentrate only on tracing the reflection of Professor Lazzarini's findings in current methodology of geodetic measurements of displacements.

The traces can be briefly characterized as follows:

\section{Displacement measurements should cover not only the structure under examination but also its surrounding}

Such a postulate is contained in the title of His famous co-authored book published in 1977. Professor Lazzarini was of the opinion that the deformations observed in the surrounding structures may provide information on future behaviour of the main monitored object The postulate is more and more important nowadays, what we can see erecting structures in deep excavations or constructing tunnels for the underground. In such cases we encounter considerable influence of construction process upon stability and strength of the surrounding structures.

\section{The method of observation differences may ensure exceptionally high accuracy of displacement determination}

He specially favoured the method of observation differences considering it a basic method of determining the displacements between the initial and the actual epoch. He himself proved, also on an experimental basis, its exceptionally high accuracy 
potential, provided that the measurement at a later epoch is carried out in a similar way as the one at an initial epoch. Nowadays, the method is still in use, but mainly in monitoring displacements of structures in the phase of their exploitation. He worked out ways how to overcome the problem of changes in network geometry resulting in the occurrence of incomplete pairs of observations in a network.

3. The reference system provided by the control network is a groundmonumented frame that allows one to integrate all the measurements and especially tie up those carried out locally

Professor Lazzarini emphasized a crucial role of geodetic reference system established around the monitored structure, claiming it an unquestionable advantage of geodetic approach over the sensor-based measurements that are carried out locally and requiring calibration of readings by tying them up to a common, externally controlled reference base. The advantages of overall reference systems offered by control networks are still invaluable nowadays.

\section{Methods of reference system identification}

Professor Lazzarini proposed identification methods based on coordinate transformations. Since His times a number of identification procedures have appeared based on analysis of network geometry or sequential network adjustments. In spite of the progress both in algorithms and computation speed the methods of Professor Lazzarini yield correct displacement vectors and satisfactorily reliable accuracy assessment.

\section{Understanding the necessity of progress in instrumentation and measuring techniques}

Professor Lazzarini attached high importance to the role of instrumentation in the process of displacement determination. He included in the above mentioned book of 1977 the chapters devoted to new (at those times) measurement techniques. So, there appeared the chapters on laser alignment and plumbing techniques as well as application of precise EDM Mecometer 3000 (written by Prof. Adam Chrzanowski), a chapter on advanced instrumentation for measurements of relative displacements (written by Prof. Wojciech Janusz), and a chapter on adaptation of photogrammetric techniques (written by Dr Irmina Laudyn).

6. In displacement measurement and analysis an interdisciplinary approach is required involving civil engineering, geotechnical engineering, hydrotechnical engineering and geodetic surveying

He called for such an approach and has given many examples of its practical implementation. The measurement systems that were formed in an interdisciplinary cooperation in those times can be concerned as precursors of the idea of structural health monitoring systems, those that are being developed nowadays for building and engineering purposes.

The problems to be solved for today or the near future are shown in Fig.1 


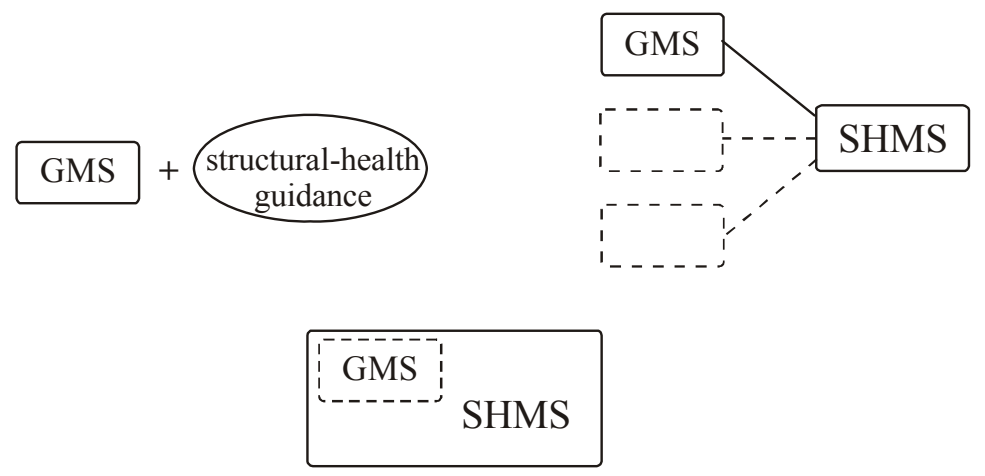

Fig.1. Expected evolutions of Geodetic Monitoring Systems for building and engineering structures

Obviously, the choice of option among those presented in Fig. 1, will depend on the type of the structure, factors affecting its behaviour, the phase of its monitoring, etc.

\section{Interpretation of measurement results}

Professor Lazzarini thought it necessary to provide, together with the computed displacements, the physical data indispensable for specialist interpretation, such as the temperature of a structure, level of water in a reservoir, wind pressure, etc,

He encouraged formation of the theory of geodetic interpretation of single point displacements, being a purely geometric analysis, meant as an introductory step to specialist interpretation that takes into account physical aspects of the structure response to loads. A chapter presenting this theory (written by Prof. Janusz) was included in His book of 1977.

\section{Being concentrated on building and engineering structures he displayed reservation towards any further transformations of a set of determined displacement vectors}

His approach is schematically presented in Fig.2. During his lectures he used to say that strict responsibility of an engineering surveyor is to deter-mine the displacement vectors of a set of points on the examined structure with appropriate accuracy and reliability. By this statement $\mathrm{He}$ sensitized engineering surveyors that for further manipulations with the displacement vectors they should enter into cooperation with structural engineers. He thought acceptable for engineering surveyors, although in consultation with structural engineers, the determination of displacement vectors for a body of the monitored structure, i.e. determination of so called rigid body movements (transformation 1 in Fig. 2). As risky and thus, not recommended operations on a set of single point displacements, He considered approximation of the displacement vector field (transformation 2 in Fig. 2) and determination of strain tensors (trans-formation 3 in Fig. 2). 


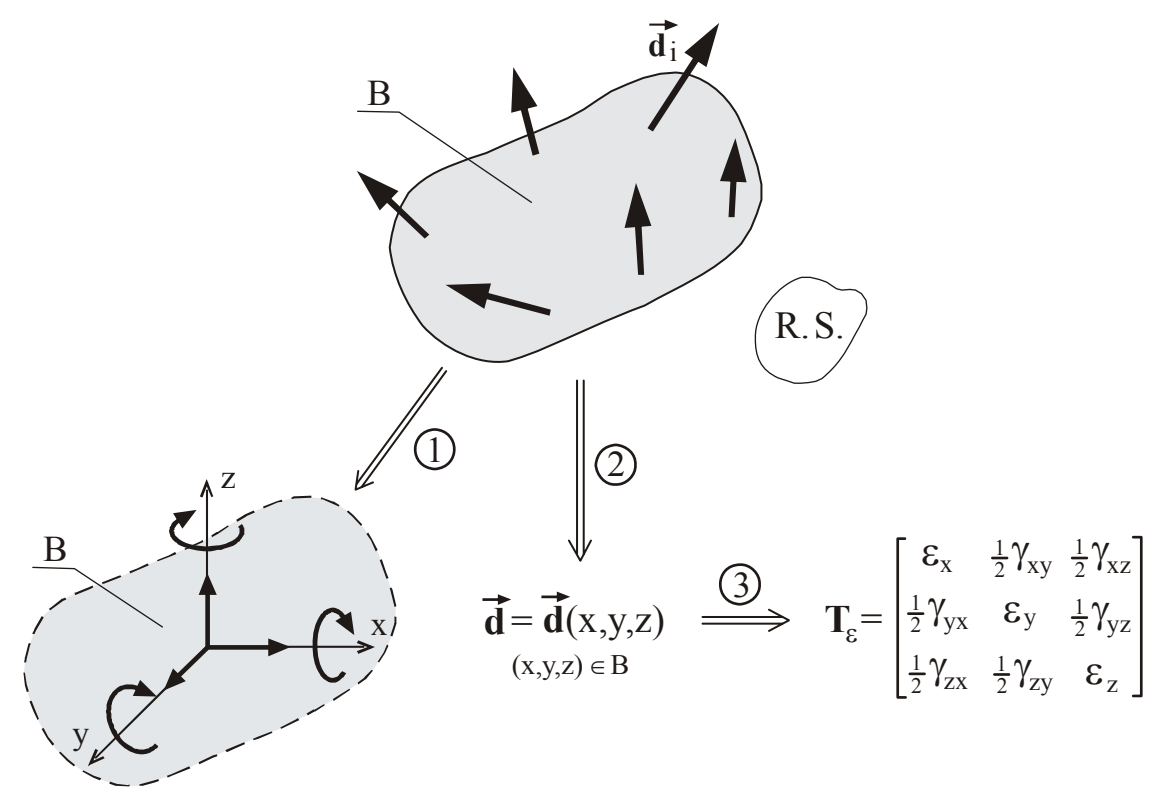

Fig.2. Possible transformations of the determined set of single point displacements 1 - acceptable transformation; 2, 3 - risky transformations (not recommended)

This attitude can be used as a warning towards incompetent use of these transformations by an engineering surveyor without professional support from the structural engineer. It is still a crucial warning for new generations of engineering surveyors.

Still today it is only the mining surveyors that are involved in determination of strains in a ground on mining areas, but they are equipped in the appropriate knowledge on rock mechanics and also, geodetic measurement techniques are especially suitable for determination of strains due to mining exploitation.

A creation in 2007 within Study Group C (FIG Commission 6) of a Task Force "Continuum Mechanics as a support for Deformation Monitoring, Analysis and Interpretation" chaired by Prof. Anna Szostak-Chrzanowski, is an attempt to form a basis for close cooperation between the engineering surveyors and specialists responsible for safety of structures. The findings of the Task Force are expected to contain indications as regards the education programmes for engineering surveyors, that would allow them to shape the observation schemes and data processing procedures to satisfy the needs of deformation analysis. The engineering surveyors might then actively participate in some further phases of the specialist analysis.

\section{Contribution to research methodology in the area of displacement measurements and analysis}

Besides laying foundation for methodology, technology and terminology of displacement measure-ments and analysis Professor Lazzarini contributed to the methodology of research in this field. He paid much attention to examination of identification procedures or accuracy assessment for dis-placements determined by the use of different measuring techniques and data processing methods.

In research He was a follower of physical experiment by using the on-site introduced displace-ments, that played a role of the true quantities. He advised not to ignore the displacements of the same sign but of the magnitude not exceeding the respective confidence intervals (or in short - the displacements statistically insignificant) as they may contain information on trends, that may shortly appear more distinctly. 
Nowadays, we readily resort to analyses on numerically simulated displacements, but perhaps the lack of contact with reality of the site may obscure for us some significant properties of the measurement process.

\section{Contribution to engineering geodesy on an international scale}

Professor Lazzarini was very active in the International Federation of Surveyors (FIG), propagating the achievements of the polish Engineering Surveying on a worldwide forum. In the term 1969 -1972 He served as Vice-chairman of FIG Commssion 6 "Engineering Surveys". His great involvement and dedication in filling this post and His high scientific level brought Him diploma of international recognition.

\section{Professor Lazzarini laid foundations for a polish school of displacement measurement and analysis, recognizable abroad}

He laid foundations for a polish school of displacement measurement and analysis being supported and followed by other researchers contributing to this field, such as Prof. Płatek, Prof. Chrzanowski, Prof. Janusz, Prof. Ney, Prof. Czaja, Prof. Hermanowski, and Dr Laudyn. Let me also mention Professor's pupils of younger generation, i.e. Dr Polak and Dr Malarski.

Professor's name is still remembered by some representatives of older generation of civil engineers, hydrological engineers and geotechnical engineers.

I conclude this brief description with a statement that Professor Lazzarini had a substantial and far-reaching contribution to the development of geodetic methods of displacement measurement and analysis. His concepts are still followed today and some of them will be valuable in shaping the methodology of deformation monitoring for tomorrow. 